\title{
INFLUÊNCIA DE MÉTODOS DE REMOÇÃO DO ARILO NA QUALIDADE FISIOLÓGICA DE SEMENTES DE Passiflora alata Curtis ${ }^{1}$
}

\author{
ELISETE APARECIDA FERNANDES OSIPI ${ }^{2}$, CRISTINA BATISTA DE LIMA², \\ CONCEIÇÃO APARECIDA COSSA ${ }^{4}$
}

RESUMO - O objetivo deste trabalho foi avaliar o efeito de diferentes métodos de remoção do arilo, na germinação de sementes e emergência de plântulas do maracujá-doce (Passiflora alata Curtis). Sementes extraídas de frutos maduros foram submetidas aos métodos de remoção do arilo: manual com fricção sobre malha de arame; manual com fricção de areia grossa sobre malha de arame; mecânico com liquidificador; biológico com fermentação à temperatura de $24^{\circ} \mathrm{C}$, por cinco dias; químico com imersão em solução de cal virgem a 10\%; químico com imersão em solução de ácido clorídrico a 37\% (1:2), ambos sob agitação por 30 minutos, e sementes sem a extração do arilo. As sementes foram avaliadas pelos testes de germinação, emergência de plântulas e índice de velocidade de emergência. $O$ delineamento estatístico foi inteiramente casualizado, com quatro repetições de 50 sementes. A remoção do arilo com friccão em malha de arame apresentou a maior eficiência de germinação em laboratório. Os métodos com fricção de areia em malha de arame, imersão em solução com cal, imersão em solução com ácido clorídrico, fermentação e a não remoção do arilo conferiram melhor desempenho às sementes em condições de viveiro. A remoção do arilo com liquidificador prejudicou a qualidade fisiológica das sementes. As condições de viveiro proporcionaram percentuais de emergência em plântulas, que superaram os resultados obtidos em condições de laboratório. Termos para indexação: Passiflora alata, arilo, germinação, emergência

\section{INFLUENCE OF METHODS OF ARYL REMOTION ON PHYSIOLOGY AND QUALITY OF Passiflora alata}

\begin{abstract}
The objective of this study was to evaluate the effect of different methods of the aryl removal, on seeds germination and seedlings emergence of sweet passion fruit (Passiflora alata Curtis). Seeds from ripe fruits were subjected to methods of removing the aryls: manual with friction on wire mesh; manual friction of coarse sand on the wire mesh; mechanical blender; biological fermentation at $24^{\circ} \mathrm{C}$, for 5 days; chemical immersion in a solution of $10 \%$ lime, and chemical immersion in hydrochloric acid solution at $37 \%$ (1:2), both chemical methods under stirring for 30 minutes and seeds without aryls. The seeds were evaluated for germination, seedling emergence and emergence speed index. Statistical design was a completely randomized, with four replications, using 50 seeds. The removal of the aryl with friction on wire mesh showed the highest germination efficiency in the laboratory. Methods with rubbing sand on wire mesh, soaking in a lime solution, immersion in hydrochloric acid, fermentation and without removing the aryl, provided better performance in the nursery conditions. The aryl removal by a blender impaired the physiological quality of seeds. The nursery conditions provided percentages of seedling emergence, which exceeded the results obtained in laboratory conditions.
\end{abstract}

Index terms: Passiflora alata, aryl, germination, emergence

\footnotetext{
${ }^{1}$ Trabalho Sinfruit 069 - Simpósio Internacional de Fruticultura - Avanços na Fruticultura (17 a 21 Outubro)

${ }^{2}$ Enga Agra Profa Doutora - Universidade Estadual do Norte do Paraná, Câmpus Luiz Meneghel- BR 369, Km 54, cp 261, 86360000, Bandeirantes-PR, Brasil. E-mail: flama@ffalm.br
} 


\section{INTRODUÇÃO}

A espécie Passiflora alata Curtis é nativa do Brasil, onde encontra excelentes condições ecológicas para seu desenvolvimento. Seu fruto, rico em minerais e vitaminas, é apreciado pela qualidade de sua polpa, aroma e sabor agradáveis, além de suas propriedades farmacológicas. O cultivo no Brasil direciona-se para o mercado de fruta in natura alcançando ótimos preços.

Embora sua propagação seja realizada por processos assexuado e sexuado, a reprodução por sementes também é utilizada comercialmente pela facilidade de realização e menor custo na produção das mudas, todavia é comum o relato do baixo percentual de germinação de suas sementes.

A germinação de sementes de maracujá é influenciada pela presença do arilo, capa de constituição gelatinosa, rica em pectina, que envolve completamente as sementes. Aliado ao fato de constituir uma barreira à germinação, o arilo pode conter substâncias reguladoras de crescimento, as quais podem contribuir para a desuniformidade na germinação (PEREIRA; DIAS, 2000). Martins et al. (2010) constataram em extratos de arilo do maracujá-amarelo substâncias inibidoras (esteroides e triterpenoides ) e redutoras (açúcares redutores) da germinação.

O método de remoção do arilo está diretamente ligado na obtenção ou não de sementes de alta qualidade, e a escolha desse método é em função das características do fruto, da maneira como se encontra aderida à semente e da presença de envelope gelatinoso envolvendo a semente (SILVA, 2000).

Conforme Carvalho e Nakagawa (2000), a extração do arilo é específica para as sementes de certas espécies, como as frutícolas, ressaltando que esse processo se torna trabalhoso e, às vezes, problemático para sementes que apresentam substâncias mucilaginosas. A fermentação, normalmente utilizada, pode ser substituída pelo emprego de substâncias químicas sem afetar a qualidade das sementes. Entretanto, cada espécie deve ser considerada individualmente, em função de suas características fisiológicas.

A propagação assexuada é prática tradicional na fruticultura, em que a utilização de sementes para a produção de mudas ocorre em um número restrito de espécies com propagação comercial sexuada. Assim sendo, a tecnologia de sementes não é desenvolvida no setor, cabendo ao viveirista ou produtor extrair, preparar e beneficiar a semente.

As pesquisas com tecnologia de sementes em espécies frutícolas no Brasil são escassas e, portanto, as regras para análise de sementes (RAS), que prescrevem os procedimentos ideais para a análise de sementes das diferentes espécies, apresentam limitações e omissões com relação a esse grupo de plantas.

Estudos para extração do arilo com processos mecânicos, químicos e biológicos em passifloráceas têm sido realizados. $\mathrm{O}$ fato da variabilidade genética existente nas espécies de passifloráceas e as variações das metodologias empregadas para um mesmo método de remoção do arilo, nas diferentes pesquisas, contribuem para os vários e contraditórios resultados existentes na literatura.

Também é interessante observar a predominância, na literatura consultada, de as pesquisas avaliarem a qualidade das sementes, realizando apenas um dos testes, em maior grau o de germinação, o qual ocorre em condições laboratoriais. Estas diferem das de viveiro, onde vários fatores atuantes, como o maior período de tempo requerido para a ocorrência da emergência, substrato, regas frequentes, entre outros, podem estar influenciando o processo.

A extração e o preparo das sementes do maracujazeiro-doce, a fim de se elevar a qualidade das mudas obtidas, carecem de estudos que possam esclarecer os fatores pertinentes, bem como contribuir para a definição de métodos eficientes e econômicos que favoreçam a qualidade fisiológica das sementes. Nesse sentido, o presente estudo teve por objetivo investigar o efeito de diferentes métodos de remoção do arilo sobre a qualidade fisiológica de sementes do maracujá-doce.

\section{MATERIAL E MÉTODOS}

A experimentação foi realizada no Laboratório de Análise de Sementes e no viveiro da Universidade Estadual do Norte do Paraná, Câmpus Luiz Meneghel - Bandeirantes. As sementes de maracujá-doce foram obtidas de trinta frutos maduros provenientes de trinta plantas de cultura de primeiro ano, instalada no município de Cornélio Procópio-PR. Os frutos foram seccionados transversalmente, e a polpa contendo sementes, mucilagem e restos placentários foi retirada com auxílio de uma colher. Esse material foi dividido em porções para a extração do arilo realizado através de sete métodos, após os quais, as sementes foram lavadas em água corrente de torneira, secas à sombra sobre papel-jornal por três dias e embaladas em saquinhos de papel por cinco dias. Os métodos para a remoção do arilo consistiram em: a) manual com fricção sobre malha de arame e água corrente de torneira até a limpeza total da mucilagem; b) manual com adição de areia grossa e fricção sobre malha de arame; c) mecanicamente, 
acionando por cinquenta vezes o botão pulsar do liquidificador, cujas hélices estavam envoltas com fita-crepe e em cujo copo foram colocados $450 \mathrm{ml}$ de polpa, mais água até completar volume de 1.000 $\mathrm{mL}$; d) fermentação à temperatura constante de $24^{\circ} \mathrm{C}$, por cinco dias, em recipiente de louça com camada de $1 \mathrm{~cm}$ de polpa; e) solução de cal extinta a $10 \%$, colocando-se $100 \mathrm{~mL}$ da solução em $150 \mathrm{~mL}$ de polpa; f) ácido clorídrico a 37\% (1: 2), colocando-se 5,5 mL da solução em $150 \mathrm{~mL}$ de polpa, ambos sob agitação por trinta minutos, e f) sementes sem remoção do arilo, apenas submetendo-as a lavagem em água corrente de torneira por alguns instantes.

$\mathrm{O}$ teste de germinação foi realizado em rolo de papel, temperatura alternada de $20-30{ }^{\circ} \mathrm{C}(16$ e 8 horas), na ausência de luz, empregando-se quatro amostras de 50 sementes por tratamento, previamente imersas por 3 minutos em solução fungicida de metalaxil-m+fluodioxonil (Maxin xl) a $0,2 \%$. As leituras foram realizadas aos 7; 14; 21 e 28 dias após a semeadura, considerando-se os percentuais de plântulas normais e anormais, as sementes não germinadas e as sementes mortas, conforme prescrição para a espécie $P$. edulis f. flavicarpa (BRASIL, 2009).

$\mathrm{O}$ teste de emergência de plântulas foi realizado no viveiro com cobertura de polietileno e sombrite a 50\%. Utilizou-se de bandejas de isopor com 288 alvéolos preenchidos com o substrato Plantimax ${ }^{\circledR}$, sendo cada parcela composta por cinquenta alvéolos contendo uma semente cada. Aplicou-se sobre o substrato, na forma de rega (2litros $/ \mathrm{m}^{2}$ ), solução fungicida à base de metalaxil-m+fluodioxonil (Maxin xl) a $0,2 \%$, no dia anterior à semeadura realizada a $1 \mathrm{~cm}$ de profundidade. As contagens, efetuadas a cada três dias, iniciaram-se com o surgimento das primeiras plântulas (36 dias após semeadura) e findaram com a estabilização (40 dias após o início). Foi considerada plântula emergida aquela que apresentava as folhas cotiledonares expandidas. A determinação da porcentagem de emergência foi efetuada, considerando-se o total de plântulas emergidas, e a determinação do índice de velocidade de emergência, através da fórmula proposta por Maguire (1962).

Os delineamentos estatísticos empregados foram inteiramente casualizados, com quatro repetições de 50 sementes por tratamento para o teste de germinação e o de emergência Os dados obtidos foram submetidos à análise de variância, e as médias, comparadas pelo teste de Tukey, a 5\% de probabilidade.

\section{RESULTADOS E DISCUSSÃO}

Os métodos utilizados para a remoção do arilo mostraram eficiência variável na germinação, assim como na emergência, já que houve diferenças entre os tratamentos em todos os testes realizados para averiguação da qualidade da semente.

\section{A - Germinação}

Os resultados são apresentados na Tabela 1, onde não consta a leitura ao sétimo dia, pela não ocorrência de plântulas normais. Estas ocorreram em maior percentual no décimo quarto dia após a semeadura, concordando com observações de Zucareli et al. (2001) e Duarte Filho et al. (1998) nas espécies $P$. cincinnata e $P$. giberti. Nesse período, destacou-se a extração do arilo pela fricção manual, seguida por fricção manual com areia e pela fermentação das sementes.

Ao final do teste de germinação, o percentual proporcionado pela remoção manual do arilo com fricção sobre malha de arame foi superior aos demais, seguido pela remoção através da fermentação, fricção com areia grossa e com liquidificador. Os tratamentos com cal, ácido clorídrico e sem a remoção do arilo prejudicaram a germinação, embora não tenham diferido da extração com liquidificador e fricção com areia.

Os resultados obtidos diferem dos observados por Martins et al. (2006), em estudo com tratamentos similares, para a remoção do arilo em sementes do maracujá-amarelo. Os autores obtiveram melhor desempenho de germinação com os métodos por fricção em malha de aço, imersão em solução de cal virgem a $10 \%$, por 10 minutos, fricção em malha de aço com areia grossa e fermentação. Já, o método com liquidificador (lâminas protegidas, ligado por 20 segundos), assim como ocorreu no presente estudo, prejudicou a germinação. O menor desempenho apresentado por esse método, provavelmente, ocorreu por causar danos que levaram à inviabilização dos embriões, o que pode ser endossado com o elevado percentual de sementes não germinadas. Costa et al. (2008) e Ferreira et al. (2008) verificaram, em teste de condutividade elétrica, que a extração com liquidificador provocou aumento de lixiviados no meio, possivelmente por ter comprometido a integridade do tegumento das sementes.

A emissão de raiz primária, em sementes do maracujá doce, foi favorecida pela remoção por fricção com areia, o que não se observou neste estudo, e prejudicada com a fermentação (PEREIRA et al., 1997). Ferreira et al. (2008) verificaram que os métodos manual, com liquidificador e fermentação, não interferiram na germinação e no envelhecimento acelerado em sementes de Passiflora cincinnata.

A fermentação vem sendo empregada há muito tempo com o objetivo de degradar o envoltó- 
rio gelatinoso que recobre as sementes, facilitando a lavagem (SILVA, 2000). Assim sendo, Pereira e Dias (2000) e Martins et al. (2006) verificaram, entre outros, que a fermentação não influenciou na germinação do maracujá-amarelo, assim como Costa et al. (2008) e Ferreira et al. (2008) observaram em outras espécies. Entretanto, assim como nesta investigação, São José e Nakagawa (1987), no maracujá-amarelo, Pereira et al. (1997) no maracujá-doce e Melo (1997), na $P$. nítida, verificaram, entre outros, que a remoção por fermentação prejudicou a germinação.

A escarificação química com cal resultou na não ocorrência de plântulas normais, discordando dos resultados obtidos com o maracujá-amarelo, por Pereira e Dias (2000) e Martins et al. (2006). Os últimos autores obtiveram, com a imersão por 10 minutos, a mesma eficiência da fricção em malha de aço, com areia grossa e fermentação. Provavelmente, o maior período de imersão (30minutos) utilizado nesta pesquisa tenha sido o fator prejudicial à germinação, o que contribuiu para a anormalidade das plântulas, uma vez que esse tratamento, assim como o de fermentação destacaram-se na ocorrência de plântulas anormais. Para Pereira e Dias (2000), a friç̧ão de sementes com cal em peneira mais água corrente não influenciou na germinação, mas quando foi avaliado o vigor pelo teste de envelhecimento acelerado, foi verificado redução significativa da qualidade fisiológica .

A utilização com ácido clorídrico (1:2) por 30 minutos não proporcionou a germinação em plântulas normais, ocasionando destaque para esse tratamento em percentual de sementes não germinadas, e discordando de Pereira e Dias (2000), que obtiveram maior qualidade fisiológica às sementes com imersão por uma hora.

O baixo percentual de germinação proporcionado pela não remoção do arilo pode ser explicado pela existência de substâncias inibidoras do processo germinativo (CARVALHO; NAKAGAWA, 2000; PEREIRA; DIAS, 2000; MARTINS et al., 2010). Estes últimos autores constataram, em extratos de arilo do maracujá-amarelo, substâncias (esteroides, triterpenoides e açúcares redutores) que interferiram direta ou indiretamente na absorção de água, inibindo a germinação da semente. Lopes et al. (2000) e Martins et al. (2010) constataram maior porcentagem de dureza (duras ou mortas) nas sementes do maracujá-amarelo. Para Martins et al. (2010), a presença do arilo pode estar relacionada à exposição das sementes a potenciais hídricos muito negativos, que impossibilitam a absorção de água pelas sementes; à presença de moléculas hidrofóbicas (triglicerídeos insaturados), dificultando a embebição por formar uma barreira na entrada de água ou, ainda, à presença de esteroides, substâncias que podem funcionar como hormônios e podem desbalancear os hormônios existentes nas sementes.

São José (1987) verificou que a presença do arilo contribuiu para reduzir o percentual de germinação, prejudicando a qualidade da semente no maracujá-amarelo, o que também foi constatado neste estudo.

As sementes mortas apresentaram baixos percentuais, não diferindo entre os tratamentos, evidenciando que estas não interferiram nos demais resultados obtidos.

\section{B- Emergência}

Em condições de viveiro (Tabela 2), os maiores percentuais de emergência foram obtidos pela remoção manual com areia grossa, com cal, ácido clorídrico, fermentação e sem remoção. Destacaram-se a remoção do arilo com fricção de areia e o tratamento com cal, proporcionando médias em torno de $60 \%$ e maior rapidez de emergência de plântulas. A extração com liquidificador prejudicou a qualidade das sementes, discordando do relatado por São José (1987), cabendo mencionar que esse autor utilizou aparelho com baixa rotação.

Cardoso et al. (2001) observaram efeito benéfico na emergência do maracujá-amarelo, cujo arilo foi removido pelo processo de fermentação, o que não foi verificado por São José (1987), que constatou efeito prejudicial. Nesse mesmo estudo, o autor verificou que a remoção manual ou por liquidificador não afetou a qualidade de sementes. Pereira e Dias (2000) constataram que a fermentação e o ácido clorídrico a 37\% (1:2), com imersão por uma hora, conferiram melhor qualidade fisiológica às sementes do maracujá-amarelo, o que concorda com os resultados obtidos nesta pesquisa

Analisando o fato de a presença do arilo nas sementes ter proporcionado emergência estatisticamente similar aos melhores resultados, não se pode deixar de supor, como relatou Lopes et al. (2007), a existência de microrganismos nessas condições, atraídos pela presença do arilo e que, ao atacá-lo, destroem a barreira ao contato imediato com a semente, além de resultar matéria orgânica na mistura.

\section{C- Considerações}

É interessante notar os comportamentos contraditórios dos tratamentos em condições de viveiro quando comparados ao teste de germinação. Os métodos com areia, cal, ácido clorídrico, fermentação e sem extração do arilo, cujos percentuais de germinação variaram de zero a $15 \%$, foram superados pela 
condição de viveiro, com 46,5 a 62\% de emergência, sugerindo que boa parte de plântulas anormais e/ou sementes não germinadas, detectadas no teste de germinação tiveram condições de se desenvolver normalmente.

TABELA 1- Porcentagens de plântulas normais (PN), plântulas anormais(PA), sementes não germinadas (SNG) e sementes mortas (SM), obtidas no teste de germinação de sementes de Passiflora alata Curtis, em função de diferentes métodos de extração do arilo.

\begin{tabular}{lccccrc}
\hline \multirow{2}{*}{ Remoção do arilo } & 14 dias & 21 dias & \multicolumn{4}{c}{$\mathbf{2 8}$ dias } \\
\cline { 5 - 7 } & PN & PN & PN & PA & SNG & SM \\
\hline Fricção manual & $33,5 \mathrm{a}^{*}$ & $11,5 \mathrm{~b}$ & $45,0 \mathrm{a}$ & $44,0 \mathrm{ab}$ & $8,5 \mathrm{~d}$ & $2,5 \mathrm{a}$ \\
Fricção manual areia & $13,0 \mathrm{~b}$ & $2,0 \mathrm{bc}$ & $15,0 \mathrm{bc}$ & $45,0 \mathrm{ab}$ & $36,0 \mathrm{bc}$ & $4,0 \mathrm{a}$ \\
Liquidificador & $1,5 \mathrm{c}$ & $6,5 \mathrm{bc}$ & $9,0 \mathrm{bc}$ & $19,0 \mathrm{c}$ & $69,0 \mathrm{a}$ & $3,0 \mathrm{a}$ \\
Fermentação & $13,0 \mathrm{~b}$ & $10,0 \mathrm{~b}$ & $23,5 \mathrm{~b}$ & $57,5 \mathrm{a}$ & $17,0 \mathrm{~cd}$ & $2,0 \mathrm{a}$ \\
Química com cal & $0,5 \mathrm{c}$ & $0,0 \mathrm{c}$ & $0,0 \mathrm{c}$ & $55,5 \mathrm{a}$ & $40,5 \mathrm{~b}$ & $4,0 \mathrm{a}$ \\
Química ác. clorídrico & $0,0 \mathrm{c}$ & $0,0 \mathrm{c}$ & $0,0 \mathrm{c}$ & $27,5 \mathrm{bc}$ & $68,5 \mathrm{a}$ & $4,0 \mathrm{a}$ \\
Sem extrair o arilo & $1,0 \mathrm{c}$ & $4,5 \mathrm{bc}$ & $5,5 \mathrm{c}$ & $43,5 \mathrm{ab}$ & $45,5 \mathrm{~b}$ & $5,5 \mathrm{a}$ \\
\hline CV(\%) & 29,03 & 41,19 & 28,96 & 19,03 & 21,57 & 46.11 \\
\hline
\end{tabular}

*Médias seguidas de mesma letra na vertical não diferem entre si, pelo teste de Tukey, a nível de 5\% de probabilidade.

TABELA 2 - Emergência de plântulas (EP) e Índice de velocidade de emergência (IVE) em sementes de Passiflora alata Curtis, preparadas com diferentes métodos de remoção do arilo.

\begin{tabular}{lcc}
\hline Remoção do arilo & EP $(\%)$ & IVE $(\%)$ \\
\hline Fricção manual & $* 41,50 \mathrm{bc}$ & $* 0,35 \mathrm{ab}$ \\
Fricção manual com areia & $62,00 \mathrm{a}$ & $0,49 \mathrm{~b}$ \\
Liquidificador & $39,00 \mathrm{c}$ & $0,30 \mathrm{a}$ \\
Fermentação & $53,50 \mathrm{abc}$ & $0,39 \mathrm{ab}$ \\
Química com cal & $60,50 \mathrm{a}$ & $0,50 \mathrm{~b}$ \\
Química com ác. clorídrico & $57,75 \mathrm{ab}$ & $0,44 \mathrm{ab}$ \\
Sem extrair o arilo & $46,50 \mathrm{abc}$ & $0,36 \mathrm{ab}$ \\
\hline CV(\%) & 15,55 & 16,96 \\
\hline
\end{tabular}

*Médias seguidas de mesma letra na coluna não diferem entre si, pelo teste de Tukey, ao nível de 5\% de probabilidade.

\section{CONCLUSÕES}

1.0 método manual de remoção do arilo com friccão em malha de arame, em sementes do maracujá-doce, proporcionou maior eficiência de germinação.

2.Os métodos com fricção de areia em malha de arame, imersão em solução com cal, imersão em solução com ácido clorídrico, fermentação e a não remoção do arilo conferiram melhor desempenho às sementes em condições de viveiro.
3.A remoção do arilo pelo método com liquidificador danificou a qualidade fisiológica das sementes de maracujá-doce.

4.Nos métodos de remoção do arilo, as condições de viveiro proporcionaram percentuais de emergência em plântulas, que superaram os resultados obtidos em condições de laboratório. 


\section{REFERÊNCIAS}

BRASIL. Ministério da Agricultura. Regras para análise de sementes. Brasília: Ministério da Agricultura, 2009. 395p.

CARDOSO, G. D. et al. Desenvolvimento de mudas de maracujazeiro-amarelo obtidas de sementes extraídas por fermentação. Revista Brasileira de Fruticultura. Jaboticabal, SP. v. 23, n. 3, p. 639-642, 2001.

CARVALHO, N.M.; NAKAGAWA, J. Beneficiamento. In:_. Sementes: ciência, tecnologia e produção. 4.ed. Jaboticabal : Funep, 2000. p.416-457.

COSTA, P. N.; FERREIRA,G.; BARON,D. Efeito de métodos de extração de arilo na qualidade fisiológica de sementes de Passiflora edulis f. flavicarpa. In: CONGRESSO BRASILEIRO DE FRUTICULTURA, 20., 2008, Vitória. Anais... Vitória: Sociedade Brasileira de Fruticultura, 2008. p.625-630.

DUARTE FILHO, J.;VASCONCELLOS, M. A. da S.; CARVALHO, C. M. Germinação de sementes de Passiflora giberti N. E. Brow sob temperatura controlada. In: SIMPÓSIO BRASILEIRO SOBRE A CULTURA DO MARACUJAZEIRO, 5., 1998, Jaboticabal. Anais... Jaboticabal: FUNEP, 1998. p.315-316.

FERREIRA, G.; COSTA, P. N.;BARON, D.; CORSATO, J. M. Avaliação da qualidade fisiológica de sementes de Passiflora cincinnata Mast. submetidas a diferentes métodos de extração. In: CONGRESSO BRASILEIRO DE FRUTICULTURA, 20., 2008, Vitória. Anais... Vitória: Sociedade Brasileira de Fruticultura, 2008. p.625-630.

LOPES, J.C. et al. Germinação e vigor de plantas de maracujazeiro-amarelo em diferentes extratos de maturação do fruto, arilo e substrato. Ciência e Agrotecnologia, Lavras, v.31, n.5, p. 1340-1346, 2007.

MAGUIRE, J.D. Speed of germinations-aid in selection and evaluation for seeding emergence vigor. Crop Science, Madison, v.2, n.2, p.176-177, 1962.
MARTINS, C. M. et al. Prospecção fitoquímica do arilo de sementes de maracujá-amarelo e influência em germinação de sementes. Ciência Rural, Santa Maria, v. 40, n. 9, p. 1934-40, 2010.

MARTINS, M. R. et al. A. Influência de diferentes métodos de remoção do arilo na germinação de sementes de maracujazeiro-amarelo (Passiflora edulis Sims f. flavicarpa deg.). Revista FZVA, Uruguaiana, v. 13, n.2, p. 28-38, 2006.

MELO, A. L.; VIEIRA, R. D.; OPLIVEIRA, J. C. Efeitos da retirada do arilo, do armazenamento e aspectos morfológicos de sementes de maracujá (Passiflora nítida H.B.K.). Informativo Abrates, Curitiba, v. 7, n. 1, p. 97, 1997.

PEREIRA, S. B. et al. Efeitos da remoção do arilo e da superação da dormência na emissão da raiz primária de sementes de maracujá-doce (Passiflora alata Dryand) - Passifloraceae. Informativo Abrates, Curitiba, v.7, n.1, p.104, 1997.

PEREIRA, K. J. C.; DIAS, D. C. F. Germinação e vigor de sementes de maracujá-amarelo (Passiflora edulis Sims f. flavicarpa Deg.) submetidas a diferentes métodos de remoção da mucilagem. Revista Brasileira de Sementes, Brasília, v. 22, n. 1, p. 288-291, 2000.

SÃO JOSÉ, A. R. Influência do método de extração na qualidade fisiológica de sementes de maracujazeiro-amarelo (P. edulis Sims. f. flavicarpa Deg). 1987. 87f. Dissertação (Mestrado em Agronomia/ Horticultura) - Faculdade de Ciências Agronômicas, Universidade Estadual Paulista, Botucatu, 1987.

SILVA, R. F. Extração de sementes de frutos carnosos. In: CARVALHO, N. M.; NAKAGAWA, J. (Ed.). Sementes: ciência, tecnologia e produção. 4.ed. Jaboticabal: Funep, 2000. p.458-484.

ZUCARELI, C. et al. Períodos de exposição a temperaturas alternadas e constantes na germinação de sementes de Passiflora alata Dryander. Informativo Abrates, Londrina, v. 11, p.308, 2001. 